\title{
A new attractant for monitoring western flower thrips, Frankliniella occidentalis in protected crops
}

\author{
Zayed S Abdullah*, Bethany PJ Greenfield ${ }^{1}$, Katherine J Ficken², James WD Taylor ${ }^{1}$, Martyn Wood ${ }^{1}$ \\ and Tariq $\mathrm{M} \mathrm{Butt}^{1}$
}

\begin{abstract}
Monitoring of pest populations is an essential component of integrated pest management. An early warning system helps growers decide when best to take control measures, or when to alter them, should a control method prove inadequate. Studies have shown that adding chemical attractants to sticky cards can increase trap catch of western flower thrips, Frankliniella occidentalis, a global pest of agriculture and horticulture, giving more accurate accounts of population size and dynamics, thus leading to more efficient monitoring. We identify a novel semiochemical to the species, (S)-(-)-verbenone, showing that addition of this compound to sticky traps significantly increased F. occidentalis catch in two geographically distinct populations, infesting two unrelated crops of global economic importance. We validate through field trials that (S)-(-)-verbenone is highly attractive to F.occidentalis and can be used with blue sticky traps to enhance trap catch, leading to better estimations of pest population densities. The compound may be used in other control methods against F.occidentalis such as lure and kill, mass trapping and push-pull.
\end{abstract}

Keywords: Frankliniella occidentalis; Semiochemical; Monitoring; (S)-(-)-verbenone; Thripline-AMS; Sticky trap

\section{Background}

Western flower thrips, Frankliniella occidentalis P. (Thysanoptera: Thripidae) is a major agricultural and horticulture pest worldwide (Kirk, 2002; Kirk and Terry, 2003). It causes damage and spoilage to a vast number of economically important plant species through feeding, oviposition and spread of several plant diseases, most notably tospoviruses (Morse and Hoddle, 2006). Their cryptic nature and small size means that they can often remain undetected through quarantine control measures, with their spread having been facilitated by the increase in international plant movement (Kiritani, 2001). A major concern is the rapid development of resistance to conventional chemical pesticides in thrips populations (Jensen, 2000; Bielza et al., 2007, Bielza, 2008). The problem is expected to increase since many pesticides have been withdrawn in the EU (Directive 2009/128/EC) highlighting the need to develop alternative control methods for this pest species.

\footnotetext{
* Correspondence: 489458@swansea.ac.uk

${ }^{1}$ College of Science, Swansea University, Singleton Park, Swansea SA2 8PP, UK

Full list of author information is available at the end of the article
}

Monitoring of pest populations is an essential component of integrated pest management. An early warning system helps growers decide when best to take control measures, or when to alter them, should a control method prove inadequate. The addition of semiochemicals to monitoring tools increases capture of pests in a wide order of insects (Bhasin et al., 2001; Light et al., 2001; Martel et al., 2005). Using knowledge of pest host specificity and/or preferences, the attractiveness of synthetic host odour blends can be maximised. Addition of optimally attractive chemicals or blends to sticky traps can increase attractiveness and sensitivity, not only providing growers with improved early warning systems, but also facilitating more accurate mapping of population densities and evaluation of the efficacy of control strategies. Such synthetic odours have been developed to enhance monitoring tools for a wide range of insect pests such as the biting midge Culicoides impunctatus (Bhasin et al., 2001), codling moth, Cydia pomonella (Light et al., 2001) and the colorado potato beetle, Leptinotarsa decemlineata (Martel et al., 2005). Furthermore, monitoring allows for the switching of control methods should a particular method cease to provide adequate population suppression, such as in the case of resistance. 
Blue and yellow sticky traps are used to monitor thrips population numbers and map their spread within a given area (Shipp 1995; Pearsall, 2002; Broughton \& Harrison, 2012). The addition of certain chemical lures to these traps can significantly increase thrips catch, both in fields and glasshouses, sometimes by as much as 100 times (Kirk, 1985; Teulon et al., 1993; Murai et al., 2000; Imai et al., 2001). Increases in trap attraction of F. occidentalis as a result of odour lures have been observed on a variety of crop types including but not limited to; pepper (Harbi et al., 2013; Teulon et al., 2014), bean (Niassy et al., 2012; Muvea et al., 2014), nectarine (Teulon et al., 2014) and strawberry (Sampson and Kirk, 2013). Furthermore, addition of odour lures to sticky traps results in more efficient mass trapping of F. occidentalis (Broughton et al., 2015), yielding increased economic benefits, particularly with high value crops (Sampson and Kirk, 2013). This paper assesses whether use of the pine pollen volatile $(S)-(-)$-verbenone, previously shown to be attractive to F. occidentalis (Abdullah et al., 2014), increases sensitivity and trap catch of F. occidentalis on sticky traps in the field, comparing trap catch to two commercially available lures. Thripline$\mathrm{AMS}^{\mathrm{TM}}$ developed at Keele University, England (Hamilton and Kirk, 2001), and produced by Syngenta Bioline Ltd (also marketed by Biobest as ThriPher), is a synthetic version of the male $F$. occidentalis pheromone neryl (S)-2-methylbutanoate. Lurem- $\mathrm{TR}^{\mathrm{TM}}$ is an interspecific kairomone attractant derived from host plants and related compounds (Davidson et al., 2007; Teulon et al., 2008b), developed by Plant Research International, the Netherlands and Crop and Food Research New Zealand (van Tol et al., 2007), and distributed by Koppert Biological Systems, the Netherlands. The semiochemicals differ in their attractiveness to different thrips species. Thripline-AMS is species-specific, attracting male and female F. occidentalis, whilst Lurem-TR is interspecific, known to attract $F$. occidentalis, as well as other thrips species (Teulon et al., 2008a; Teulon et al., 2008b).

\section{Results}

\section{Release rates of verbenone}

A total ion chromatogram of $(S)$-(-)-verbenone volatile capture from each sachet loading is included in the electronic supplementary material (Additional file 1). Release rates of verbenone from sachets, as per surface coverage of the SPME fibre of the release surface, can be seen in Figure 1. An average release rate of $0.9 \mu \mathrm{g} / \mathrm{hour}$ was released from the $0.5 \mathrm{mg}$ verbenone loading, $4.9 \mu \mathrm{g} / \mathrm{hour}$ was released from the $5 \mathrm{mg}$ verbenone loading and $17.7 \mu \mathrm{g} /$ hour was released from the $50 \mathrm{mg}$ verbenone loading. This corresponds to a $1: 5.4: 19.7$ (0.5 $\mathrm{mg}$ : $5 \mathrm{mg}$ : $50 \mathrm{mg}$ ) release ratio difference between the different loadings. The absolute release rates in the field

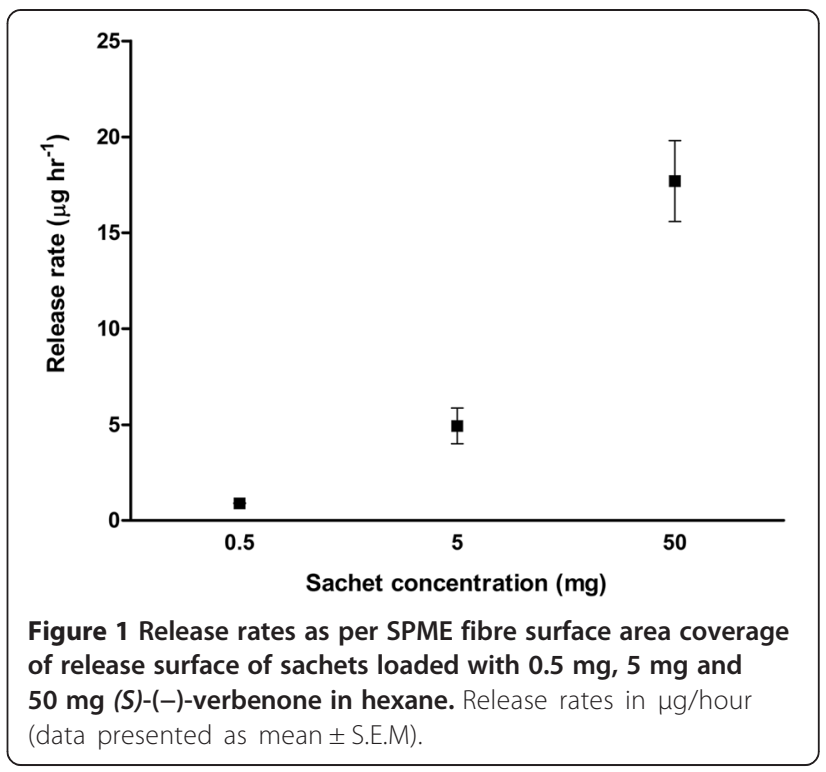

would have been much greater, as the method described only samples a relatively small area of the release surface. Furthermore, daily fluctuations in wind speeds and temperature would have resulted in varied release rates at given times (Murlis et al., 1992). Further peak enlargement was observed with a 10 minute exposure to the largest lure concentration, discounting the possibility of fibre saturation. No compounds with a similar retention time were observed in the background air of the laboratory.

\section{Thrips identification}

In both experiments, there were primarily two morphologically similar thrips types on the sticky cards and flower tapped samples that were noticeably different in size (Additional file 2), and in the UK experiment, a relatively larger black thrips species was observed, individuals of which were excluded from the counts. Both of the morphologically similar types were found to have red ocelli, antennae comprising of eight antennal segments (with the two end segments being smaller than the others), and a prothorax containing four pairs of the larger 'strong' bristles with one pair at each corner, confirming them to be Frankliniella spp.. However, the method of identification did not distinguish between species within the genus. Figure 2 illustrates the bands formed from restriction enzyme digestions of the ITS2 region, from the larger and smaller thrips samples collected from Herefordshire, UK. PCR amplification attempts of thrips recovered from the sticky cards were unsuccessful, most likely due to DNA degradation, hence the thrips obtained from the flower tapped samples were used for molecular analysis. The band formation for both types was consistent with Frankliniella 


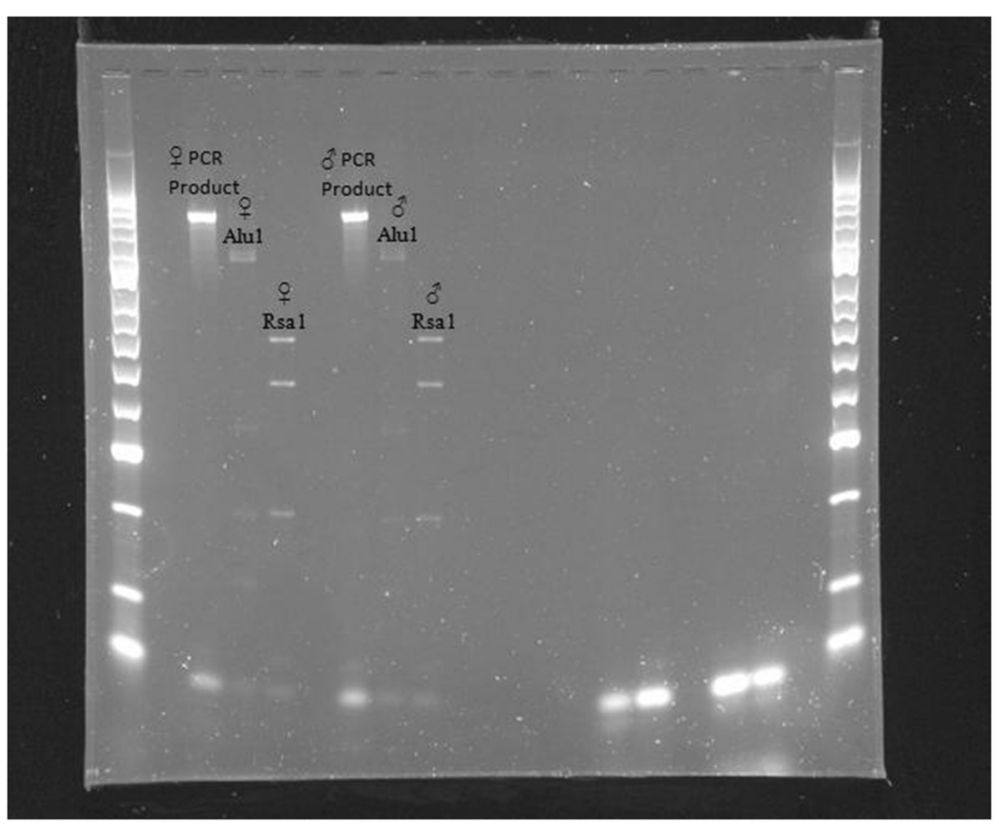

Figure 2 Gel visualization of band formation from morphologically distinct (smaller and larger) thrips collected in Herefordshire, UK. Band patterns confirm that both specimens were male and female western flower thrips.

occidentalis, thus confirming the larger specimens were female and the smaller specimens male, which was supported by the morphological identification. DNA extraction and PCR amplification of samples collected from Turkey were unsuccessful, presumably due to the significant DNA degradation attributable to the longer transportation and storage time before analysis. Therefore, the thrips caught in these trials could not be identified to the species level, and shall be referred to as Frankliniella spp.

\section{Trap catches}

Figure 3 illustrates the results from the UK trials. There was no significant difference in trap catch between the Thripline $\mathrm{AMS}^{\mathrm{Tn}}$ treatment and the hexane control $(F(5,80)=3.781, \mathrm{p}=0.116)$. There was a significant increase in trap catch for $(S)-(-)$-verbenone treatments at $0.1 \%(F(5,80)=3.781, \mathrm{p}=0.008), 1 \%(F(5,80)=3.781$, $\mathrm{p}=0.003)$ and $10 \%(F(5,80)=3.781, \mathrm{p}=0.029)$ concentrations. The highest mean trap catch was observed on the sticky traps containing Lurem- $\mathrm{TR}^{\mathrm{m} \mathrm{m}}$ treatment, which was significantly different than the control treatment of hexane alone $(F(5,80)=3.781, \mathrm{p}=0.002)$.

Results from the Turkey trials are shown in Figure 4. Three sticky traps were omitted from the experiment, as it was found during the 24 hour count that they had not been adequately setup. These included a blank sticky trap in glasshouse 3, a Lurem-TR ${ }^{\mathrm{Tu}}$ treated sticky trap in glasshouse 6 and an ethyl acetate treated sticky trap, also in glasshouse 6. In general, higher mean trap catches were observed than in the UK trials. There was no significant difference in trap catch of Frankliniella spp. between the blank sticky card treatment and the ethyl acetate treatment $(F(3,108)=7.235, \mathrm{p}=0.057)$. There was a significant increase in trap catch observed for the $1 \%(S)-(-)$-verbenone $(F(3,108)=7.235, \mathrm{p}<0.001)$ and Lurem- $\operatorname{TR}^{\text {mix }}(F(3,108)=7.235, \mathrm{p}<0.001)$ treatments compared to the blank sticky card control.

\section{Discussion}

The results of the UK trials corroborated previous studies that showed application of Lurem-TR ${ }^{\mathrm{Tm}}$ increases mean sticky trap catches of $F$. occidentalis (Teulon et al., 2007; Broughton and Harrison, 2012; Muvea et al., 2014; Teulon et al., 2014; Broughton et al., 2015). The (S)-(-)-verbenone treatments significantly increased trap catches at all concentrations, demonstrating the sensitivity of $F$. occidentalis to the compound, as previously demonstrated by electrophysiological and behavioural laboratory based assays (Abdullah et al., 2014). Furthermore, both (S)-(-)-verbenone and Lurem-TR ${ }^{\mathrm{mw}}$ treatments increased sticky trap catch of two geographically distinct populations of Frankliniella spp., infesting two families of economically important crops, indicating that host odours did not reduce the trap catch efficacy of these two semiochemicals for both commodities.

The results in the UK trials were mirrored in the trials in Turkey where the same treatments were applied, even though ethyl acetate was used as a diluent instead of hexane. Ethyl acetate was observed to increase thrips 


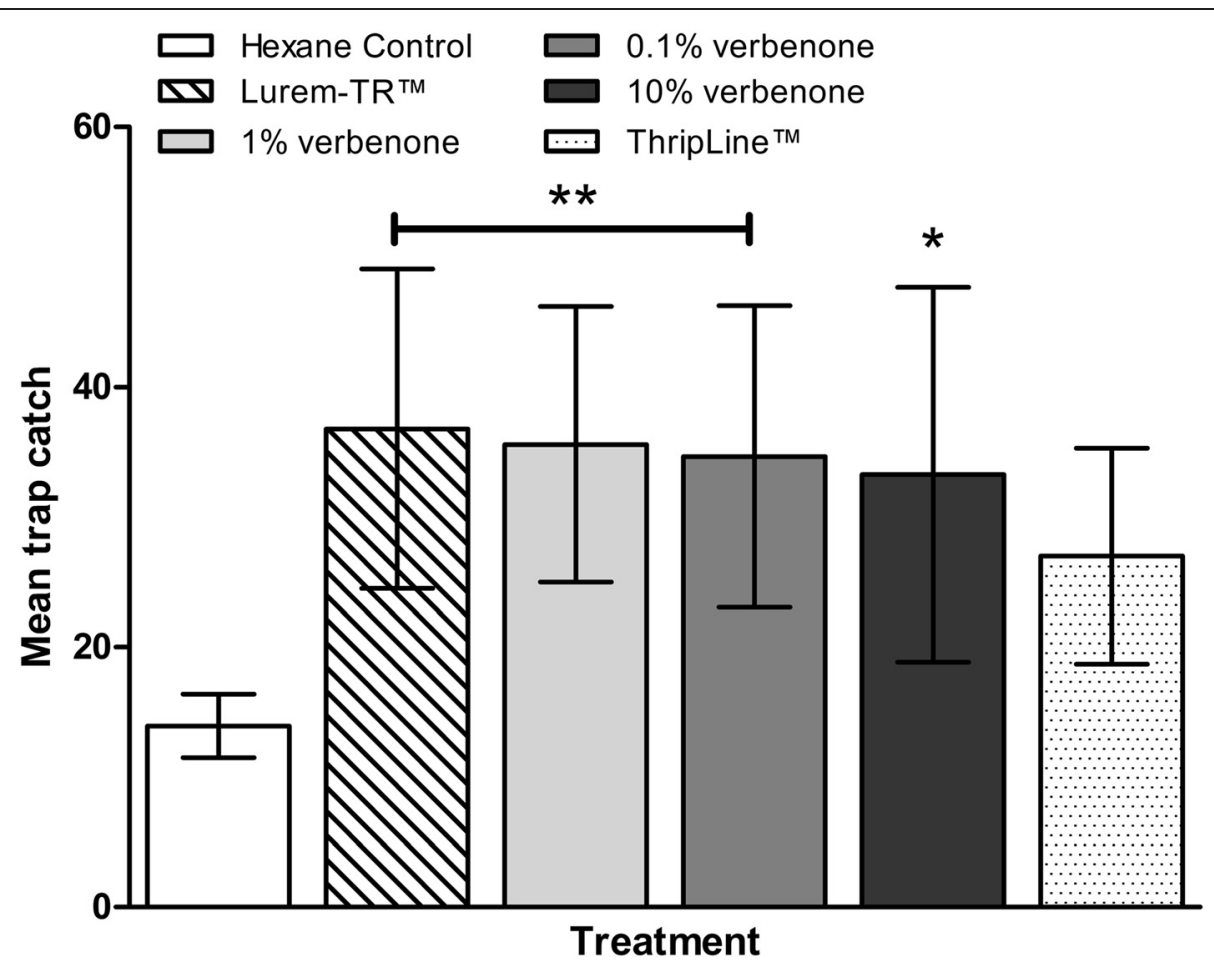

Figure 3 Data represents untransformed means of $\mathbf{2 4}$ hour trap catch of $F$. occidentalis in Herefordshire, UK. Square root transformed count data was analysed using a general linear model. Means were separated using Dunnett's post-hoc, with $\mathrm{P}=0.05$ considered significantly different when compared to hexane control (data presented as mean $\pm 95 \%$ C.I., ${ }^{*}=P<0.05,{ }^{* *}=P<0.01, N=15$ per treatment).

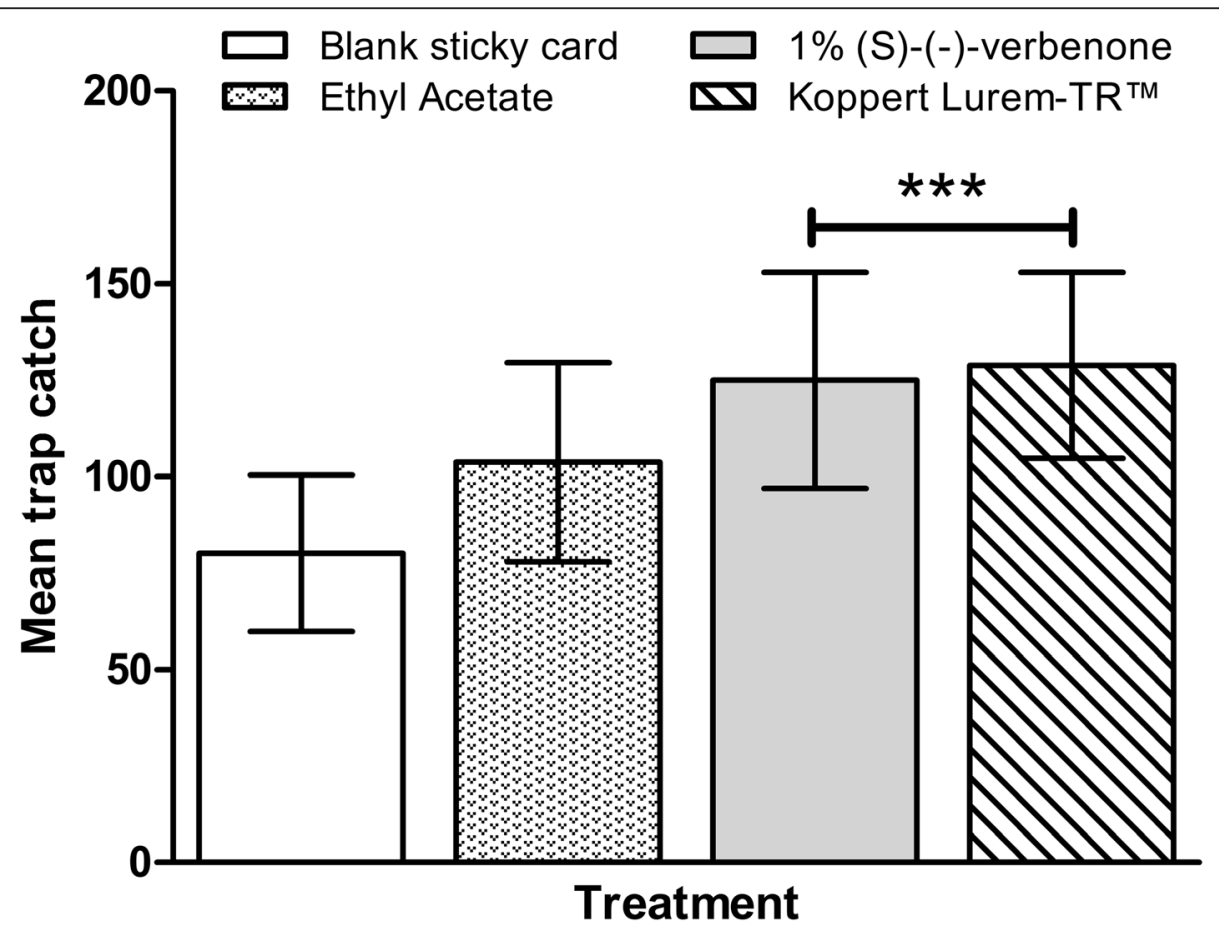

Figure 4 Data represents untransformed means of $\mathbf{2 4}$ hour trap catch of Frankliniella spp. in Antalya, Turkey. Square root transformed count data was analysed using a general linear model. Means were separated using Dunnett's post-hoc, with $P=0.05$ considered significantly different when compared to blank control (data presented as mean $\pm 95 \%$ C.I., ${ }^{* * *}=P<0.001$. $N=\geq 29$ per treatment). 
preference to a treatment area within a 4-arm olfactometer, and elicit a significant electrophysiological antennal response (Abdullah et al., 2014), but no significant attraction was observed in the field. Ethyl acetate has been documented to attract a wide order of insects, including but not limited to species of; Diptera (CasanaGiner et al., 1999), Coleoptera (Smilanick et al., 1978), Collembola (Bengtsson et al., 1991) and Hymenoptera (Dicke et al., 1984).

In week one of two of the five experiments carried out by Broughton et al., 2015, Lurem-TR ${ }^{\mathrm{T} w}$ caught significantly more $F$. occidentalis than Thripline-AMS ${ }^{\mathrm{TM}}$ and the control, mirroring the results of the UK trials in this study. In the other two experiments, there were similar trap captures across the Lurem-TR ${ }^{\mathrm{mx}}$, Thripline-AMS ${ }^{\mathrm{mx}}$ and control treatments, where all treatments caught thrips in relatively less abundance, and in the fifth experiment both Lurem-TR ${ }^{\mathrm{im}}$ and Thripline-AMS ${ }^{\mathrm{mix}}$ caught significantly more than the control (Broughton et al., 2015). The results of this experiment highlight some variability in the capture potential of the Thripline$\mathrm{AMS}^{\mathrm{Tm}}$, and the consistency of Lurem-TR ${ }^{\mathrm{mm}}$.

In general, higher mean trap catches were observed in the Turkey trials than in the UK trials, and this may have occurred due to a number of reasons. Firstly, the temperatures recorded in the Turkey trials were much higher than those recorded in the UK trials. This may have increased thrips' populations in the glasshouses in Turkey compared to the polytunnels in UK, resulting in a greater trap catches. Other environmental factors may have also contributed to the increased mean trap catches in turkey, including less wind in the enclosed glasshouses compared to open-ended polytunnels which may have effects thrips' flight, greater amounts or different types of light reflecting off the sticky traps in the glasshouses compared to the polytunnels as a result of the comprising materials, or the fact that the infested crops in Turkey were better hosts for F.occidentalis, therefore resulting in higher population numbers within the plants. Additionally, the efficacy of the traps may have been reduced as a result of interference between treatments in the UK trials due to wind movement patterns through the open-ended polytunnels. As the glasshouses in the Turkey trials were enclosed, wind would movement would have been less likely to result in interferences between treatments.

\section{Conclusions}

We have demonstrated the efficacy of a simple kairomone release sachet, which is cheaper to produce than many commercially available release matrixes, and can be used in combination with sticky traps and semiochemicals to increase trap catches of insects. Verbenone is widely used in perfumery, and can therefore be purchased at lower costs than most thrips pheromone analogues, the production of which requires specialized synthesis. We have shown that such a release sachet impregnated with (S)-(-)-verbenone can significantly increase sticky trap catches of Frankliniella spp., a globally important pest of agriculture and horticulture, to a level similar to another commercially available product over 24 hours. We validated the efficacy of a novel semiochemical to enhance trap catches of this insect, thus showing its potential as a monitoring tool. The compound may be used in other control methods against Frankliniella spp. such as lure and kill, mass trapping and push-pull. We have demonstrated an increase in attractiveness of two geographically disctinct Frankliniella spp. when (S)-(-)-verbenone is added to sticky traps catch, with pests infesting unrelated commodities of global economic importance. The findings have resulted in the publication of patent WO 2014091185 A1 (Butt and Abdullah, 2014). There is further scope to improve trap catch even more using a blend of other attractive compounds, particularly ones that act on different olfactory receptor neurons. Further evaluations should focus on the range of activity this compound induces in other thrips species, and other insect groups and orders.

\section{Methods}

\section{Trap design and lures}

Blue sticky traps (Suterra, Pontypridd, Wales) measuring $10 \mathrm{~cm} \times 25 \mathrm{~cm}$, containing a black dashed grid on one face, which comprised of $1 \mathrm{~cm}^{2}$ squares were used in this experiment. Counts were made on the gridded area which covered $10 \mathrm{~cm} \times 18 \mathrm{~cm}$ of the lower area of the sticky card. The chemical (S)-(-)-verbenone (94\%, CAS No. 1196-01-6, Sigma Aldrich, UK) was impregnated at different concentrations in 'Sweet Scent' sachets (Suterra, Pontypridd, Wales) to determine optimal dose. The sachets were made up of a cellulose pad $(6 \mathrm{~cm} \times 1 \mathrm{~cm} \times 0.1 \mathrm{~cm})$ enclosed within a high density polyethylene sachet, which had a $0.3 \mathrm{~cm}$ diameter hole in the centre of one surface from which the volatiles emanated. The sachets were made to $0 \%$ (500 $\mathrm{mg}$ hexane), $0.1 \%$ (0.5 $\mathrm{mg}$ in $500 \mathrm{mg}$ hexane), $1 \%(5 \mathrm{mg}$ in $500 \mathrm{mg}$ hexane) and $10 \%$ (50 mg in $500 \mathrm{mg}$ hexane) concentrations for the UK trial and 0\% (500 mg ethyl acetate) and $1 \%$ (5 mg in $500 \mathrm{mg}$ ethyl acetate) for the Turkey trial. The lures were packaged in heat sealed foil sachets (Additional file 3). Commercially available Thripline $\mathrm{AMS}^{\mathrm{Tm}}$ impregnated in rubber septa (Syngenta Bioline, England) and Lurem-TR ${ }^{\text {in }}$ (Koppert Biological Systems, The Netherlands) were used to compare efficacy of verbenone trap catch to presently available commercial lures. The major active component of Thripline AMS ${ }^{\mathrm{m}}$ is the western flower thrips' aggregation pheromone neryl S-methylbutanoate (Hamilton et al., 2005). The 
major active ingredient of Lurem- $\mathrm{TR}^{\mathrm{Tm}}$ is the plant kairomone methyl isonicotinate (Teulon et al., 2011). All lures were stored at $-20^{\circ} \mathrm{C}$ or as per manufacturer's guidelines and were used within a week of receiving. The 'Sweet Scent' sachets were stapled to the top of the sticky traps, above the count grid, stapling the outer heat sealed edges of the sachet so as not to affect release rates. The Lurem-TR ${ }^{\mathrm{Tu}}$ lures were fastened to the plant twist ties used to hang the sticky traps, ensuring that the bottom of the lure positioned roughly in the same region of the trap that the 'Sweet Scent' lures were attached. The Thripline $\mathrm{AMS}^{\mathrm{m}}$ septa were fitted into the single hole at the top centre of the traps, as per the manufacturer's guidelines.

\section{Release rates of lures Volatile collection}

Release ratios of (S)-(-)-verbenone from lures was calculated using solid phase microextraction (SPME). An exposed 50/30 DVB/Carboxen ${ }^{\text {Tw }} /$ PDMS StableFlex ${ }^{\text {Tw }}$ SPME fiber (Gray Fiber, Supelco) was laid over the diameter of the sachet hole, resting on the HDPE sachet. The fiber, which was contained in a manual holder, was held in place using a clamp stand, ensuring that the fiber did not come into contact with the saturated cellulose pad within the sachet. The fiber was retracted after 5 minutes of adsorption, after which the volatiles were desorbed and analyzed using gas chromatography coupled mass spectroscopy (GC-MS). A $0.1 \mu \mathrm{l}$ solution containing $100 \mathrm{ng}$ of $(S)-(-)$-verbenone in hexane was added to the fiber as an in-fiber standard. To ensure that the fiber had not become saturated within 5 minutes of sampling the highest dose lure, an additional 10 minute adsorption was done to ensure further enlargement of the peak, thus ensuring that the fiber had not become saturated. Additionally, to eliminate the possibility of peak enlargement due to (S)-(-)-verbenone or compounds with a similar retention time in the laboratory air, a 5 minute adsorption of the room air was carried out at various intervals. 3 replicates were carried out in this fashion for each dosage of lure diluted in hexane and the (S)-(-)-verbenone in-fiber standard. An additional replicate was carried out for $1 \%$ verbenone diluted in ethyl acetate, to ensure there was no difference in release rate as a result of the diluent.

\section{Gas chromatography coupled mass spectroscopy}

Gas chromatography/mass spectroscopy (GC/MS) analysis was carried out on a HP6890 gas chromatograph coupled to a 5975 inert Mass Selective Detector (Agilent Technologies) operated in electron impact ionization (EI) mode (at $70 \mathrm{eV}$ ). SPME fibers were inserted into the GC split/splitless injection port (at $230^{\circ} \mathrm{C}$ ), fitted with a Merlin Microseal (Thames-Resteck, High-Wycombe, UK), operating in splitless mode. Fibers were desorbed for 2 minutes. The GC was fitted with a HP-5MS (J and W Scientific) fused silica capillary column $(30 \mathrm{~m} \times$ $0.25 \mathrm{~mm} \times 0.25 \mathrm{~mm}$ film thickness). The oven temperature was held at $40^{\circ} \mathrm{C}$ for 2 minutes and then increased by $10^{\circ} \mathrm{C} \cdot \mathrm{min}^{-1}$ to $250^{\circ} \mathrm{C}$.

\section{Thrips identification \\ Morphological identification}

It was considered impractical to confirm the identity of all of the thrips on the sticky cards due to the high catch numbers; hence only thrips in the bottom left corner of the sticky trap grids were subjected to identification. The thrips were visually identified using a light microscope at $\times 10$ magnification. Thrips were confirmed to be Frankliniella spp. only if the Ocelli were observed to be red, the antennae comprised eight antennal segments (with the two end segments being smaller than the others) and the prothorax contained four pairs of the larger 'strong' bristles, with one pair at each corner (Moritz et al., 2004).

\section{Restriction fragment length polymorphism identification}

Further identification of thrips was done using restriction fragment length polymorphism (RFLP) analysis of the internal transcribed spacer region 2 (ITS2) of the ribosomal DNA, as per a method described by Moritz et al., 2002.

Comparisons of the base-pair product bands from representative samples were compared to those of confirmed species on a commercially available molecular key (Moritz et al., 2004).

Briefly, DNA was extracted placing $\sim 100$ individual thrips from each trial site in a $1.5 \mathrm{ml}$ Eppendorf tube and adding liquid nitrogen. The thrips were ground up to a fine powder using a sterile micro pestle, adding $100 \mu \mathrm{l}$ of AP1 lysis buffer (DNeasy ${ }^{\circ}$ Plant Mini DNA Extraction Kit, Qiagen, Netherlands) and heating the tubes at $65^{\circ} \mathrm{C}$ for 30 minutes. $15 \mu \mathrm{l}$ of cold $8 \mathrm{M}$ potassium acetate was then added and the tube was incubated on ice for 15 minutes, after which the tubes were centrifuged for 20 minutes at $10,000 \times \mathrm{g}$. The supernatant was transferred to a new $1.5 \mathrm{ml}$ Eppendorf tube and the same volume of isopropanol was added followed by centrifugation at $10,000 \times \mathrm{g}$ for 15 minutes. The pellet was washed twice with $70 \%$ ethanol, dried, and re-suspended in $16 \mu \mathrm{l}$ sterile dnase-free water (Qiagen, Netherlands). The ITS2 region was amplified using the primers 28Z 5' AGACTCCTTGGTCCGTGTTTC3' (Hillis and Dixon, 1991) and P1 5'ATCACTCGGCTCGTGGATCG3' (Severini et al., 1996). Anhydrous primers were purchased from a commercial supplier (Eurofins Scientific, Luxembourg), adding water and storing tubes as per manufacturers guidelines. Each PCR mixture contained $0.5 \mu \mathrm{l}$ $28 \mathrm{Z}$ primer, $0.5 \mu \mathrm{l} \mathrm{P1}$ primer, $5 \mu \mathrm{l}$ of extracted DNA solution, $6.5 \mu \mathrm{l}$ of dnase-free water and $12.5 \mu \mathrm{l}$ of REDtaq ${ }^{\circ}$ 
ReadyMix $^{\text {Tw }}$ PCR Reaction Mix (Sigma, United Kingdom) to a final volume of $25 \mu \mathrm{l}$. The amplification was carried out in a Thermal Cycler (PTC-200 Peltier, M) Research, USA). The DNA was initially denatured at $94^{\circ} \mathrm{C}$ for $2 \mathrm{mi}-$ nutes followed by 30 cycles of denaturation at $94^{\circ} \mathrm{C}$ for 30 seconds, annealing at $55^{\circ} \mathrm{C}$ for 30 seconds and elongation at $72^{\circ} \mathrm{C}$ for 2 minutes. The last cycle was followed by a 10 minute incubation period at $72^{\circ} \mathrm{C}$ to complete any partially synthesized strands. Upon purifying the amplified DNA using a commercial kit (PCR Purification Kit, QIAquick', Qiagen, Netherlands), RFLP digestions of amplified ITS2 regions were done using the commercially produced restriction enzymes Alu1 (R6281, Promega, USA) and Rsa1 (R6371, Promega, USA), following manufacturers guidelines. Digestion products were visualized on a $1 \%$ agarose gel containing $6 \mu$ of gel red nucleic acid stain $(10,000 \times$ in water, Biotium, USA), comparing products to a $100 \mathrm{bp}-2,000 \mathrm{bp}$ ladder (HyperLadder 2, Bioline Reagents Ltd, United Kingdom).

\section{Field locations and crop types}

Two field trials were carried out in separate geographic locations, concomitantly. One field trial was conducted in a set of polytunnels in Herefordshire, UK, at: N 51 $56^{\prime}$ $32.0^{\prime \prime}, \mathrm{W} 2^{\circ} 41^{\prime} 45.2^{\prime \prime}$. A second field trial was conducted in commercial glasshouses in Antalya, Turkey, at: N $37^{\circ} 01^{\prime}$ 04.05", E $30^{\circ} 56^{\prime} 58.74 "$.

The UK trial site consisted of a set of open-ended polytunnels $(7.5 \mathrm{~m} \times 270 \mathrm{~m})$ containing five rows of growing beds with mixed age strawberry plants, Fragaria $x$ ananassa var. Elsanta. In Turkey, trials were conducted on pepper plants, Capsicum annuum var. Kapya, in enclosed commercial glasshouses $(20 \mathrm{~m} \times 80 \mathrm{~m})$. Plants were of similar age within each polytunnel or glasshouse.

\section{Experimental setup UK poly tunnel trials}

Blue sticky traps were hung with plant twist ties $(B \& Q$, $\mathrm{UK}), 30 \mathrm{~m}$ from entrance of the poly tunnel, to ensure even wind distribution across the experimental setup. Sticky traps were hung parallel to one another $50 \mathrm{~cm}$ above the outer-most beds, in a randomized block design with a $10 \mathrm{~m}$ separation between traps along the right most and left most beds. Five replicate poly-tunnels (blocks) were used with three replicates per treatment. Trials consisted of six treatments, including: hexane sachet (control), three concentrations of (S)-(-)-verbenone, Lurem-TR ${ }^{\mathrm{ma}}$ and Syngenta Thripline-AMS ${ }^{\mathrm{ma}}(\mathrm{n}=15$ per treatment). Counts were recorded at midday $\left(36^{\circ} \mathrm{C} \pm 2^{\circ} \mathrm{C}\right)$, $24 \mathrm{hr}$ after traps were set.

\section{Turkey glass house trials}

Turkey trials consisted of six replicate glass houses (blocks), with five replicates of each treatment per block.
Trials contained four treatments; blank blue sticky traps (control), ethyl acetate only, $1 \%(S)-(-)$-verbenone in ethyl acetate and Lurem-TR ${ }^{\mathrm{m} x}(\mathrm{n}=30$ per treatment). Ethyl acetate was used as a diluent in this trial as an alternative to hexane, due to the finding that it was electrophysiologically active and marginally attractive to F. occidentalis (Abdullah et al., 2014), as well as being less toxic. Sticky traps were hung over the outer-most pepper beds closest to the walls of the glasshouse, with a $7 \mathrm{~m}$ separation. Counts were recorded at midday $\left(41^{\circ} \mathrm{C} \pm 2^{\circ} \mathrm{C}\right), 24 \mathrm{hr}$ after traps were set.

\section{Counts}

Counts of $F$. occidentalis on cards were made using a tally counter (Scientific Laboratory Supplies Ltd, Nottingham, UK). Only insects caught within the grid area were counted, recording insects caught on both side of the trap. Sticky traps were collected for subsequent morphological and molecular identification of thrips in the laboratory. The presence of thrips species were sampled by collecting $>5$ individuals in the field, at random, from flowers below each trap in each block, storing the samples in ethanol for subsequent morphological and molecular identification in the laboratory.

\section{Statistical analyses}

Comparison of trap catches with and without lures was analysed using a general linear model (GLM). The model incorporated fixed effects of treatment, including block number as a random factors. Means were compared using a Dunnet's post-hoc test. Prior to analysis trap catch data was subjected to square root transformation, conforming to GLM assumption of homogeneity of variance, which was confirmed using levene's test of equality of error variances. All statistical analyses were carried out using SPSS software (IBM Corporation, USA).

\section{Additional files}

Additional file 1: Total ion chromatogram of (S)-(-)-verbenone volatile capture from each sachet loading.

Additional file 2: Thrips sample collected from experiment site.

Additional file 3: Sweet Scent' sachet lure and packaging.

\section{Abbreviations}

HDPE: High-density polyethylene; GC-MS: Gas chromatography coupled mass spectroscopy; SPME: Solid phase microextraction; RFLP: Restriction fragment length polymorphism; GLM: General linear model.

Competing interests

The authors declare that they have no competing interests.

Authors' contributions

ZSA drafted the manuscript, designed the studies, carried out the field trials in UK, conducted morphological and RFLP identification, conducted SPME and GC-MS work. BPJG assisted with data analysis. KJF assisted with GC-MS analysis. JWDT and MW conducted field trials in Turkey. TMB assisted with 
drafting the manuscript, contributed to design of the studies and coordination and sourced the funding to carry out the research. All authors read and approved the final manuscript.

\section{Acknowledgements}

We thank students and staff from Swansea University (UK) and Adnan Menderes University (Turkey) as well as the growers who helped with the trials. We would also like to thank Alper Altinok and colleagues for their assistance with logistical support. This work was supported by the European Social Fund (ESF) through the Knowledge Economy Skills Scholarships (KESS) under Grant: 80300 and Suterra LLC.

\section{Author details}

${ }^{1}$ College of Science, Swansea University, Singleton Park, Swansea SA2 8PP, UK. '2Department of Geography, Swansea University, Singleton Park, Swansea SA2 8PP, UK.

\section{Received: 2 November 2014 Accepted: 29 January 2015 Published online: 24 February 2015}

\section{References}

Abdullah ZS, Ficken KJ, Greenfield BPJ, Butt TM (2014) Innate responses to putative ancestral hosts: thrips' pine pollen preference the result of relict receptors? J Chem Ecol 40(6):534-540

Anon, Directive 2009/128/EC of the European Parliament and of the council of 21 October 2009 (2009) Establishing a framework for community action to achieve the sustainable use of pesticides. Off J Eur Comm L309:71, 24.11.2009

Bengtsson G, Hedlund K, Rundgren S (1991) Selective odour perception in the soil Collembola Onychiurus armatus. J Chem Ecol 17:2113-2125

Bhasin A, Mordue Luntz AJ, Mordue W (2001) Field studies on efficacy of host odour baits for the biting midge Culicoides impunctatus in Scotland. Med Vet Entomol 15:147-156

Bielza P (2008) Insecticide resistance management strategies against the western flower thrips, Frankliniella occidentalis. Pest Manag Sci 64:1131-1138

Bielza P, Quinoto V, Contreras J, Torne M, Martin A, Espinosa PJ (2007) Resistance to spinosad in the western flower thrips, Frankliniella occidentalis (Pergande), in greenhouses of south-eastern Spain. Pest Manag Sci 63:682-687

Broughton S, Harrison J (2012) Evaluation of monitoring methods for thrips and the effect of trap colour and semiochemicals on sticky trap capture of thrips (Thysanoptera) and beneficial insects (Syrphidae, Hemerobiidae) in deciduous fruit trees in Western Australia. Crop Prot 42:156-163

Broughton S, Cousins DA, Rahman T (2015) Evaluation of semiochemicals for their potential application in mass trapping of Frankliniella occidentalis (Pergande) in roses. Crop Prot 67:130-135

Butt TM, Abdullah ZSA (2014) Use of a compound to control insects. WO2014091185 A1

Casana-Giner V, Gandia-Balaguer A, Primo-Yufera E (1999) Field trial of an attractant mixture for dipterous, including the pest Ceratitis capitata (Wiedemann) (Dipt, Tephritidae), in Valencia. Spain J Appl Entomol 123:47-48

Davidson MM, Butler RC, Winkler S, Teulon DAJ (2007) Pyridine compounds increase trap capture of frankliniella occidentalis (pergande) in a covered crop. N Z Plant Prot 60:56-60

Dicke M, van Lenteren JC, Boskamp GJF, van Dongen-Leeuwen E (1984) Chemical stimuli in host-habitat location by Leptopilina heterotoma (Thomson) (Hymenoptera: Eucoilidae), a parasite of Drosophila. J Chem Ecol 10:695-712

Hamilton JGC, Kirk WDJ (2001) Method of monitoring/controlling thrips. WO03/055309 A1

Hamilton JGC, Hall D, Kirk WDJ (2005) Identification of a male-produced aggregation pheromone in the western flower thrips, Franliniella occidentalis. J Chem Ecol 31:1369-1379

Harbi A, Elimem M, Chermiti B (2013) Use of a synthetic kairomone to control Frankliniella occidentalis Pergande (Thysanoptera: Thripidae) in protected pepper crops in Tunisia. Afr J Plant Sci Biotechnol 7:42e47

Hillis DM, Dixon T (1991) Ribosomal DNA: Molecular evolution and phylogenetic interference. Q Rev Biol 66:411-453

Imai T, Maekawa M, Murai T, Imai T, Maekawa M (2001) Attractiveness of methyl anthranilate and its related compounds to the flower thrips, Thrips hawaiiensis (Morgan), Thrips coloratus (Schmutz), Thrips flavus (Schrank) and
Megalurothrips distalis (Karny) (Thysanoptera : Thripidae). Jpn J Appl Entomol Z 36(4):475-478

Jensen SE (2000) Insecticide resistance in the western flower thrips, Frankliniella occidentalis. Integrated Pest Manag Rev 5:131-146

Kiritani K (2001) Invasive insect pests and plant quarantine in Japan. Ext Bull Food Fertilizer Center Taipei 498:1-12

Kirk WDJ (1985) Effect of some floral scents on host finding by thrips (Insecta, Thysanoptera). J Chem Ecol 11(1):35-43

Kirk WDJ (2002) The pest and vector from the West: Frankliniella occidentalis. In: Marullo R, Mound LA (eds) Thrips and Tospoviruses: Proceedings of the Seventh International Symposium on Thysanoptera. Australian National Insect Collection, Canberra, pp 33-44

Kirk WD, Terry LI (2003) The spread of the western flower thrips, Frankliniella occidentalis (Pergande). Agric Forest Entomol 5(4):301-310

Light DM, Knight AL, Henrick CA, Rajapaska D, Lingren B, Dickens JC et al (2001) A pear derived kairomone with pheromonal potency that attracts male and female codling moth, Cydia pomonella (L). Natuurwet 88:333-338

Martel JW, Alford RA, Dickens JC (2005) Synthetic host volatiles increase efficacy of trap cropping for management of colorado potato beetle, Leptinotarsa decemlineata. Agric Forest Entomol 7:71-78

Moritz G, Paulsen M, Delker C, Picl S, Kumm S (2002) Identification of thrips using ITS-RFLP analysis. In: Thrips and Tospoviruses: Proceedings of the 7th International Symposium on Thysanoptera (eds R Marullo \& LA Mound). Australian National Insect Collection, Canberra, Australia, pp 365-367

Moritz G, Mound LA, Morris DC, Goldarazena A (2004) Pest thrips of the world, visual and molecular identification of pest thrips. Interactive CD ROM distributed by Lucid. University of Queensland, Australia

Morse JG, Hoddle MS (2006) Invasion biology of thrips. Annu Rev Entomol 51:67-89

Murai T, Imai T, Maekawa M (2000) Methyl anthranilate as an attractant for two thrips species and the thrips parasitoid Ceranisus menes. J Chem Ecol 26(11):2557-2565

Murlis J, Elkinton JS, Cardé RT (1992) Odor plumes and how insects use them. Annu Rev Entomol 37:505-532

Muvea AM, Waiganjo MM, Kutim HL, Osiemo Z, Nyasani JO, Subramanian S (2014) Attraction of pest thrips (Thysanoptera: Thripidae) infesting French beans to coloured sticky traps with Lurem-TR and its utility for monitoring thrips populations. Int J Trop Insect Sci 34(3):197-206

Niassy S, Maniania NK, Subramanian S, Gitonga LM, Ekesi S (2012) Performance of a semiochemical-baited autoinoculation device treated with Metarhizium anisopliae for control of Frankliniella occidentalis on French bean in field cages. Entomol Exp Appl 142:97-103

Pearsall IA (2002) Daily flight activity of the western flower thrips (Thysanoptera: Thripidae) in nectarine orchards in British Columbia, Canada. J Appl Entomol 126:293-302

Sampson C, Kirk WDJ (2013) Can mass trapping reduce thrips damage and is it economically viable? Management of the western flower thrips in strawberry. PLoS One 8:e80787

Severini C, Severini F, Mancini P, La Rosa G, Marinucci M (1996) Sequence and secondary structure of the rDNA second internal transcribed spacer in the sibling species Culex pipiens L. and CX. quinquefasciatus Say (Diptera: Culicidae). Insect Mol Biol 5:181-186

Shipp JL (1995) Monitoring of western flower thrips on glasshouse and vegetable crops. In: Parker BL, Skinner M, Lewis T (eds) Thrips biology and management. Plenum, New York, pp 547-555

Smilanick JM, Ehler LE, Birch MC (1978) Attraction of Carpophilus spp. (Coleoptera: Nitidulidae) to volatile compounds present in figs. J Chem Ecol 4:701-707

Teulon DAJ, Hollister B, Cameron EA (1993) Behavioural responses of western flower thrips to anisaldehyde, and implications for trapping in greenhouses. Bulletin OILB/SROP 16(2):177-180

Teulon DAJ, Nielsen M, James D (2007) Combination of two odour chemical lures does not increase thrips capture in field bioassays. N Z Plant Prot 66:61-66

Teulon DAJ, Davidson MM, Nielsen M-C, Perry NB, van Tol RWHM, De Kogel WJ (2008a) In: Mason PG, Gillespie DR, Vincent R (eds) Proceedings of the Third International Symposium on Biological Control of Arthropods, Christchurch, New Zealand, The Potential Use of Lures for Thrips Biological Control in Greenhouses: Practice and Theory., pp 301-308

Teulon DAJ, Nielsen M-C, de Kogel WJ, van Tol RWHM, Davidson MM (2008b) A new lure for Thrips major. N Z Plant Prot 61:386 
Teulon DAJ, Davidson MM, Perry NB, Nielsen M-C, van Tol RWHM, de Kogel WJ (2011) Recent developments with methyl isonicotinate, a semiochemical used in thrips pest management. N Z Plant Prot 64:287

Teulon DAJ, Castañé C, Nielsen M-C, El-Sayed AM, Davidson MM, Gardner-Gee R et al (2014) Evaluation of new volatile compounds as lures for western flower thrips and onion thrips in New Zealand and Spain. N Z Plant Prot 67:175-183

van Tol R, de Kogel WJ, Teulon D (2007) New compound catches more thrips. In: FloraCulture International., pp 22-23

Submit your manuscript to a SpringerOpen ${ }^{\circ}$ journal and benefit from:

- Convenient online submission

- Rigorous peer review

- Immediate publication on acceptance

- Open access: articles freely available online

- High visibility within the field

- Retaining the copyright to your article

Submit your next manuscript at $\gg$ springeropen.com 